CDD: 128.2

\title{
É INCOERENTE A CONCEPÇÃO DE SEARLE SOBRE A CONSCIÊNCIA?
}

\author{
Tárik de Athayde Prata \\ Departamento de Filosofia \\ Universidade Federal de Pernambuco (UFPE) \\ Centro de Filosofia e Ciências Humanas (CFCH) \\ 150 andar, Cidade Universitária \\ Recife - PE \\ BRASIL \\ tarikbilden@yahoo.de
}

\section{Received: 20.09.2010; Revised: 23.02.201 I; Accepted: 06.05.20I I}

\begin{abstract}
Resumo: $O$ artigo investiga a frequente alegação na literatura filosófica de que a concepção de Searle sobre a redução da consciência é incoerente. Após um exame das teses básicas de sua teoria da mente (seção 2), é discutida sua posição a respeito da identidade entre a consciência e a atividade cerebral (seção 3). Da adesão de Searle a uma tese da identidade de ocorrências deve-se concluir que não há contradição entre esta tese e a irredutibilidade ontológica que ele defende. Porém, é possível deduzir de sua teoria asserções que contradizem esta mesma teoria (seção 4), uma vez que essa irredutibilidade resulta em um dualismo de propriedades (seção 5).
\end{abstract}

Palavras chave: Consciência, redução, sobredeterminação causal, epifenomenalismo.

\begin{abstract}
The article investigates the frequent assertion in the philosophical literature which affirms that Searle's conception of the reduction of consciousness is incoherent. After an exam on the basic theses of his theory of mind (section 2), his position concerning the identity between consciousness and brain activity is discussed (section 3). From Searle's adhesion to a token identity thesis, we can conclude that there is no contradiction between this thesis and the ontological irreducibility he defends. However, it is possible to deduce assertions from his theory that contradict this same theory (section 4) once this irreducibility results in a property dualism (section 5).
\end{abstract}

Keywords: Consciousness, reduction, causal overdetermination, epiphenomenalism.

Manuscrito - Rev. Int. Fil., Campinas, v. 34, n. 2, p. 557-578, jul.-dez. 2011. 


\section{INTRODUÇÃO ${ }^{1}$}

Apesar de se encontrar entre os filósofos mais influentes da atualidade $^{2}$, o norte-americano John R. Searle parece não ter tido na área da filosofia da mente um sucesso tão grande quanto em outros ramos do fazer filosófico. Mesmo que, por um lado, suas ideias a respeito da consciência ${ }^{3}$ tenham grande ressonância entre aqueles que se dedicam ao estudo do cérebro, entre seus pares não faltam avaliações bastante negativas sobre sua teoria das relações entre mente e corpo, por ele chamada de naturalismo biológico (cf. Searle (1992, p. 1)). Alguém poderia retrucar que isso é uma consequência do fato de Searle defender pontos de vista bem peculiares, distantes, por exemplo, do funcionalismo (a concepção mais influente na filosofia da mente contemporânea). De fato, muitos dos críticos do naturalismo biológico

\footnotetext{
${ }^{1}$ Gostaria de agradecer a Guido Imaguire (UFRJ), pela discussão a respeito do trabalho, e a Maxwell Morais de Lima Filho (UFAL) pelos proveitosos debates sobre Searle ao longo dos últimos anos. Agradeço também aos pareceiristas anônimos da Manuscrito, pela leitura cuidadosa do meu trabalho, e por suas preciosas sugestões, e a Raquel do Monte, pela revisão do texto.

${ }^{2}$ Uma clara evidência da importância de Searle na filosofia atual é o grande número de congressos internacionais e publicações (em periódicos e editoras de grande reconhecimento) dedicado à discussão de suas idéias. Cf. por exemplo Kim, Jakob, et. al. (1995), Vanderveken, et. al. (2001), Grewendorf, Meggle, (Eds.) (2002), Preston, Bishop, (Eds.) (2002), Smith, (Ed.) (2003), Tsohatzidis, (Ed.) (2007).

${ }^{3}$ Deixo de lado aqui a crítica do autor ao modelo computacional da mente (baseada no famoso "argumento do quarto chinês" - cf. Searle, 1980a), tema que, a rigor, também integra sua filosofia da mente (pois diz respeito à Intencionalidade dos fenômenos mentais) e me concentro em sua teoria positiva acerca da consciência. O motivo para essa restrição é que essa teoria da consciência dá margem às suspeitas de incoerência que serão examinadas a seguir. Sobre o modo como Searle concebe a consciência cf. os seguintes textos: Searle (1992, p. 83); (2002a, pp. 7, 21, 38); (2004, p. 136-7).
}

Manuscrito - Rev. Int. Fil., Campinas, v. 34, n. 2, p. 557-578, jul.-dez. 2011. 
são expoentes do fisicalismo por ele criticado (cf. Stich (1987); Dennett (1993); Churchland (1994)). Mas é um fato digno de nota que uma das críticas mais recorrentes ao naturalismo biológico (a de que esta seria uma teoria incoerente) se encontra também em autores aversos ao mainstream fisicalista (cf. Nagel (1993)).

A acusação de incoerência é encontrada frequentemente na literatura (cf. Crane (1993); Olafson (1994); Snowdon (1994); Corcoran (2001)) e ela me parece especialmente contundente quando são consideradas as ideias de Searle acerca da noção de redução. Reconstituindo de modo mais detalhado as teses defendidas por Searle, procurei mostrar em um trabalho anterior (cf. Prata (2008)) que a concepção do autor sobre a redução da consciência (na medida em que ele afirma, simultaneamente, a redutibilidade causal e a irredutibilidade ontológica desta última a processos cerebrais) conduz a uma série de inconsistências no que diz respeito às suas capacidades causais. Das diversas teses defendidas por ele a respeito da consciência, seria possível deduzir conclusões que contradizem algumas dessas teses (cf. Prata (2008, p. 21-2)):

(1) A consciência é causalmente eficaz sobre o comportamento humano (cf. Searle (2004, p. 207));

(2) As capacidades causais da consciência são as mesmas dos processos cerebrais (cf. Searle (2004, p. 127));

(3) Processos cerebrais causam o comportamento humano (cf. Searle (1983, p. 269-70));

(4) A consciência e os processos cerebrais não são idênticos (cf. Searle (1992, p. 117); (2004, p. 119));

(5) O comportamento humano tem apenas um tipo de causa, não é sobredeterminado (cf. Searle (2002b, p. 62)); 
de (1), (3) e (4) segue-se:

$\left(\mathrm{C}_{1}\right)$ O comportamento humano tem dois tipos de causas, é sobredeterminado.

de (3), (4) e (5) segue-se:

$\left(\mathrm{C}_{2}\right)$ A consciência não é causalmente eficaz sobre o comportamento humano.

Penso que a tese que exige uma consideração mais atenta para avaliar se essas contradições realmente se seguem é a tese da nãoidentidade - isto é, a tese (4) - que se encontra nas passagens em que Searle afirma a irredutibilidade ontológica da consciência a processos cerebrais. A tese (4) exige uma consideração mais atenta até porque para as outras teses envolvidas (1, 3 e 5 ) se encontram bons argumentos no campo da filosofia e das neurociências (de modo que o problema deve estar na suspeita tese 4 - que expressa um dualismo ontológico considerado pouco promissor dos dias de hoje). Mas essa tese parece exigir mais atenção por uma razão ainda mais profunda: pelo fato de que a posição de Searle acerca dela é ambígua (e essa ambiguidade na atitude do autor acerca do tema é o que gera a contradição ou, no mínimo, a aparência de contradição em sua teoria). Por um lado, ele sustenta explicitamente a tese (4) em diversas passagens como, por exemplo, quando ele afirma que "a consciência é, de modo completo, causalmente explicável pelo comportamento neuronal, mas não é, em virtude disso, mostrada como sendo nada além de comportamento neuronal' (Searle (2004, p. 119), grifo meu; cf. também (1992, p. 117); (2002b, p. 60)).

Por outro lado, quando se observa a argumentação de Searle para a tese (2) acima - a identidade entre as capacidades causais da consciência e dos processos cerebrais -, pode-se constatar que ele acaba defendendo o oposto da tese (4), uma vez que a identidade das 
capacidades causais seria decorrente da identidade dos entes em questão, como transparece na seguinte passagem: "Posso, com razão, dizer tanto que minha dor causou meu desejo quanto que sequências de descargas neuronais causaram outras sequências. Esses são duas descrições diferentes, embora consistentes, do mesmo sistema, dadas em níveis diferentes" (Searle (1995, p. 219), grifo meu; cf. também (2004, p. 127-8)).

Essa passagem, usada por Searle para alicerçar a tese (2), parece expressar uma identidade que é incompatível com a irredutibilidade ontológica, fazendo a incoerência em sua teoria parecer flagrante. Basta pensar na descrição de uma chapa de aço em termos da solidez no nível macro, por um lado, e em termos dos movimentos moleculares correspondentes no nível micro, por outro lado. Pensar na consciência nos termos de uma propriedade como a solidez parece implicar que a consciência é ontologicamente redutível. Assim, formulei a tese defendida na passagem citada acima (Searle (1995, p. 219)) da seguinte maneira:

(6) A consciência e os processos cerebrais são a mesma entidade em diferentes níveis de descrição (cf. Prata (2008, p. 27))

Ou seja, além da contradição entre a conclusão $\left(\mathrm{C}_{1}\right)$ e a tese (5), por um lado, e a conclusão $\left(\mathrm{C}_{2}\right)$ e a tese (1), por outro lado, haveria uma contradição entre duas das teses básicas da teoria de Searle, a saber, as teses (4) e (6).

O presente trabalho visa esclarecer se o naturalismo biológico realmente padece dessas incoerências, ou se, diante de uma formulação mais adequada de suas teses básicas, elas se mostram ilusórias. Para isso será seguido o seguinte percurso: primeiramente serão examinadas de modo detalhado as teses fundamentais do naturalismo biológico (seção 2). Em seguida, será discutido em que sentido Searle concebe a identidade entre consciência e processos cerebrais (seção 3), para então 
serem examinadas as consequências dessa concepção de identidade para a questão das capacidades causais da consciência (seção 4). Defenderei a tese de que a contradição entre (4) e (6) é ilusória, mas, por outro lado, defenderei que as conclusões $\left(\mathrm{C}_{1}\right)$ e $\left(\mathrm{C}_{2}\right)$ se seguem do naturalismo biológico (o que faz dele, sim, uma concepção incoerente) porque ele está comprometido com um dualismo de propriedades (seção 5).

\section{AS TESES FUNDAMENTAIS DO NATURALISMO BIOLÓGICO}

Desde que passou a se dedicar à filosofia da mente, Searle defende a sua solução para o problema mente-corpo (cf. Searle (1980b, p. 455)), por ele chamada de "naturalismo biológico" (cf. Searle (1983, p. 264)). Essa concepção positiva da mente (oferecida como alternativa após a negação do modelo computacional e demais concepções fisicalistas da mente) se baseia nas teses de que os fenômenos mentais, cujo mais importante é a consciência, ${ }^{4}$ são causados por processos cerebrais no micronível e realizados no sistema cerebral no macronível (cf. p. ex. Searle (1994, p. 545)). Dessa simultânea causação e realização (para ele algo muito comum na natureza) resultaria que os fenômenos mentais são fenômenos biológicos, como a digestão, a mitose ou a secreção de enzimas (cf. Searle (1992, p. 1)). Mas há uma quarta tese que desempenha um papel fundamental na teoria de Searle, a tese de que os fenômenos mentais têm um modo de existência subjetivo, na medida em que eles só existem quando são vivenciados por um sujeito (cf. Searle (2002a, p. 41)). Justamente em virtude desse modo de existência subjetivo, os

\footnotetext{
${ }^{4}$ A consciência recebe atenção especial nas reflexões de Searle simplesmente porque ela, de acordo com ele, é o mais importante dos fenômenos mentais: "A razão para enfatizar a consciência numa explicação da mente é que ela é a noção mental central. De um modo ou de outro, todas as outras noções mentais - como intencionalidade, subjetividade, causação mental, inteligência etc. - só podem ser plenamente compreendidas como mentais por meio de suas relações com a consciência" (Searle, 1992, p. 84).
}

Manuscrito - Rev. Int. Fil., Campinas, v. 34, n. 2, p. 557-578, jul.-dez. 2011. 
fenômenos mentais conscientes seriam ontologicamente irredutíveis a fenômenos objetivos (como os processos cerebrais), tal como é formulado em uma passagem citada acima (cf. Searle (2004, p. 119)). Temos assim quatro teses básicas do naturalismo biológico de Searle o sinal “*” visa diferenciar estas teses daquelas apresentadas na introdução do presente trabalho. Todas as vezes em que esse sinal estiver ausente, tratam-se das teses reconstituídas em Prata (2008):

(1*) A consciência é causada por processos cerebrais.

$\left(2^{*}\right)$ A consciência é uma propriedade sistêmica do cérebro.

(3*) A consciência é um fenômeno biológico.

(4*) A consciência é ontologicamente irredutivel a fenômenos objetivos.

Sem grande esforço é possível perceber uma tensão entre as três primeiras teses (que parecem ter um caráter fisicalista) e a última, que expressa, em termos bastante gerais, um dualismo ontológico em relação à consciência. A esse respeito é importante notar que Searle concebe a subjetividade como uma característica que distingue os fenômenos mentais de tudo o mais que existe, pois, nas palavras dele: "estados e processos conscientes possuem uma característica especial não possuida por outros fenômenos naturais, a saber, a subjetividade" (Searle (1992, p. 93), grifo meu). Logo após a passagem citada ele deixa claro que ele tem em mente a subjetividade ontológica (um modo de existência).

A tensão entre essas teses se torna ainda mais evidente quando se analisa uma série de consequências delas. A causação da consciência por processos cerebrais - tese $\left(1^{*}\right)$ - tem, segundo Searle, a consequência de que a consciência é causalmente redutivel a tais processos ${ }^{5}$

${ }^{5}$ Searle apresenta a redutibilidade causal da consciência à atividade cerebral como uma consequência de sua causação por processos neurobiológicos: "Sustento uma visão de relações mente/cérebro que é uma forma de redução 
e a redução causal implica, por sua vez, duas condições (cf. Searle (2002b, p. 60)): que as características da consciência são explicáveis em termos de processos cerebrais e que suas capacidades causais são as mesmas que as destes processos. Conforme uma passagem citada na introdução acima (Searle (1995, p. 219); cf. também (2004, p. 127-8)), a argumentação de Searle para essa identidade dos poderes causais parece basear-se em um certo tipo de identidade entre os fenômenos em questão, uma vez que estaríamos lidando com o mesmo sistema em diferentes níveis de descrição. Essa identidade seria confirmada pela tese $\left(2^{*}\right)$, na qual a consciência é uma propriedade sistêmica do cérebro, ou seja, uma propriedade que não pode ser atribuída às seus constituintes básicos, mas apenas ao sistema (ou a partes dotadas da devida complexidade) ${ }^{6}$, de modo que a descrição do sistema no nível macro e a descrição no nível de seus componentes fundamentais são descrições da mesma entidade.

O panorama acima delineado, que resulta na tese $\left(3^{*}\right)-$ a consciência é um fenômeno biológico - parece incompatível com a tese (4*), na medida em que a irredutibilidade ontológica tem, por um lado, uma consequência aparentemente inconciliável com a redutibilidade causal, a saber, que as características da consciência não podem ser expressas em termos objetivos (como os que designam os processos cerebrais) e, por outro lado, a irredutibilidade ontológica implica que as propriedades ontologicamente subjetivas e objetivas não são idênticas (cf. Searle (1992, p. 117)). Os problemas internos do naturalismo biológico se mostram com clareza quando se considera cuidadosamente as teses discutidas acima. As teses cujo número é seguido de "a" ou "b" são consequências das teses marcadas com "*”, já a tese marcada com " $X$ "

causal, conforme defini a noção: características mentais são causadas por processos neurobiológicos" (Searle (1992, p. 115)).

6 "Neurônios individuais não são conscientes, mas porções do cérebro compostas de neurônios são conscientes" (Searle (2004, p. 114), grifo meu).

Manuscrito - Rev. Int. Fil., Campinas, v. 34, n. 2, p. 557-578, jul.-dez. 2011. 
é uma condição da tese a ela correspondente (tal como Searle a entende).

(1*) A consciência é causada por processos cerebrais.

(1a) As características da consciência são causalmente explicáveis através dos processos cerebrais.

(1b) As capacidades causais da consciência são as mesmas que as dos processos cerebrais.

(2*) A consciência é uma propriedade sistêmica do cérebro.

(3*) A consciência é um fenômeno biológico.

(4*) A consciência é ontologicamente irredutivel a fenômenos objetivos.

(4a) As características da consciência não podem ser expressas em termos objetivos.

(4×) As características subjetivas e objetivas são diferentes.

O exame destas teses básicas do naturalismo biológico e de suas implicações propicia um entendimento muito mais seguro e abrangente dessa teoria (enquanto que as teses formuladas por mim em Prata (2008) ficaram restritas - exceto a tese (4) - apenas ao tema das capacidades causais da consciência), e tal entendimento é indispensável para que se possa julgar sua coerência. Para realizar esse julgamento, cabe agora examinar mais detidamente as teses $(1 \mathrm{~b})$ e $(2 *)$, por um lado, e $(4 \times)$, por outro, pois as duas primeiras têm como consequência algum tipo de identidade entre a consciência e os processos cerebrais, enquanto a terceira tese corresponde ao modo como Searle, efetivamente, concebe a diferença entre eles. 


\section{DE QUE NOÇÃO DE IDENTIDADE SE TRATA?}

Os indícios de que o naturalismo biológico contém algum tipo de asserção de identidade entre a consciência e os processos cerebrais são numerosos e estão presentes desde o seu surgimento. Nos primeiros escritos de Searle sobre filosofia da mente já se encontra a afirmação de que as descrições de estados mentais e processos do cérebro se referem à mesma coisa em diferentes níveis (cf. Searle (1980b, p. 455)), e no seu influente livro sobre a Intencionalidade existem diversas passagens onde, no meu modo de entender, a referida identidade é afirmada ou sugerida (cf. Searle (1983, p. 265, 266, 269, 270)). Tais indícios levaram alguns autores a formar a interpretação de que Searle defendia, nos anos de 1980, uma variante da teoria da identidade mente-cérebro (cf. Place (1988), Schröder (1992)). E, conforme apresentado na introdução acima, existem passagens em textos mais recentes onde ele se compromete com a tese da identidade entre a consciência e a atividade cerebral (cf. Searle (1995, p. 219); (2004, p. 127-8)). Mas como compreender uma tal identidade diante da irredutibilidade ontológica? Há de fato uma incoerência do naturalismo biológico a esse respeito? Ou é possível, de alguma maneira, compatibilizar as duas teses?

Penso que uma indicação importantíssima para responder a essas questões foi dada por Searle em um de seus últimos livros (2004). No quarto capítulo desse livro ele discute os pressupostos errôneos que, segundo ele, têm dificultado a solução do problema mente-corpo. Entre eles, uma determinada concepção de identidade. As considerações de Searle vão no sentido de descartar o uso da noção de identidade nas discussões a respeito do problema mente-corpo, uma vez que (apesar de funcionar bem no caso de objetos e de compostos - cf. Searle (2004, p. 110)) ela não seria aplicável ao caso dos eventos, uma categoria ontológica que é, usualmente, considerada mais relevante para a discussão a respeito dos fenômenos mentais. 
Como coloca Steward (2003), após a derrocada do dualismo de substâncias, o problema mente-corpo passou a ser formulado com novos recursos ontológicos: "Diferentes maneiras de conceber o modo de existência de entidades tais como crenças, pensamentos e sensações deram origem a uma nova ontologia da mente, na qual eventos, estados e processos mentais substituíram as modificações da alma" (Steward (2003, p. 2)). Entre as categorias citadas pela autora, a categoria dos eventos tem tido um destaque especial, em virtude da influência das ideias de Donald Davidson a respeito do problema mente-corpo (cf. Ibid., p. 4).

De acordo com Searle, no caso dos eventos mentais, não seria possível encontrar critérios claros de identidade, em virtude de uma ambiguidade fundamental: tais eventos possuiriam tanto propriedades neurobiológicas quanto propriedades subjetivas. Por isso a noção de identidade deveria ser descartada. Mas o fato é que, apesar de não considerar a noção de identidade adequada para a discussão do problema mente-corpo, Searle, ao argumentar para essa inadequação, descreve a relação dos eventos mentais com suas propriedades de um modo que, claramente, o compromete com a tese da identidade de ocorrências, e, no meu modo de entender, essa tese permite dissipar a aparente contradição entre identidade e irredutibilidade ontológica. Discutindo a noção de identidade, a respeito da consciência e do cérebro, Searle traça uma determinada concepção dos eventos mentais baseada na explicação de Jaegwon Kim sobre a identidade de ocorrências. Nas palavras do autor:

O caso é um pouco como o exemplo de Jaegwon Kim para a identidade de ocorrências. Toda ocorrência de objeto colorido é idêntica a uma ocorrência de objeto dotado de forma. Não há dúvida de que isso é verdadeiro, mas isso não mostra que ser colorido e ter uma forma são a mesma coisa. Do mesmo modo, podemos ter uma noção de processo neurobiológico grande o suficiente de modo que toda ocorrência de processo de dor é uma ocorrência de processo neurobiológico no cérebro, mas disso não se segue que a sensação

Manuscrito - Rev. Int. Fil., Campinas, v. 34, n. 2, p. 557-578, jul.-dez. 2011. 
dolorosa de primeira pessoa é a mesma coisa que o processo neurobiológico de terceira pessoa (Searle, 2004, p. 125, grifos meus).

Essa concepção se encaixa perfeitamente com a concepção de identidade de ocorrências que Kim apresenta no texto ao qual Searle se refere nessa passagem. A formulação de Kim é a seguinte: "todo evento que cai sob um tipo de evento mental também cai sob um tipo de evento físico (ou todo evento que tem uma propriedade mental também tem alguma propriedade física)" (Kim (1996, p. 59)). Sendo assim, não há a contradição entre as teses (4) e (6) sugerida por mim em Prata (2008, p. 27), pois a tese (4) é uma negação da identidade entre propriedades subjetivas e objetivas, enquanto que a tese (6) é a afirmação de que tais propriedades pertencem aos mesmos eventos. Ao caracterizar a irredutibilidade ontológica da consciência aos processos do cérebro, Searle nos diz que as características (features) subjetivas são diferentes das características objetivas (cf. Searle (1992, p. 117)), o que é perfeitamente compatível com a situação de que tais características pertençam a um mesmo evento particular.

O panorama da situação é o seguinte: determinados eventos que ocorrem no cérebro possuem propriedades tanto no nível micro quanto no nível macro. Nos dois níveis eles possuem propriedades objetivas ( $\mathrm{p}$. ex. propriedades eletroquímicas das sinapses isoladas - no nível micro e p. ex. propriedades eletroquímicas dos eventos que ocorrem nos nervos inteiros, no nível macro), porém, no nível macro, alguns dos eventos que ocorrem em um sistema cerebral possuem também propriedades subjetivas (referentes ao aspecto qualitativo). Assim, as propriedades subjetivas (relativas à consciência) ${ }^{7}$ e objetivas (relativas

\footnotetext{
7 A consciência, na concepção de Searle, abrange os diversos estados, eventos e processos mentais que ocorrem efetivamente a um sujeito em um dado momento, sendo que tais fenômenos mentais seriam características (features), isto é, propriedades do cérebro: "dores e outros fenômenos mentais são apenas características do cérebro (e talvez do resto do sistema nervoso central)" (Searle (1984, p. 19), grifado no original).
}

Manuscrito - Rev. Int. Fil., Campinas, v. 34, n. 2, p. 557-578, jul.-dez. 2011. 
aos eventos cerebrais) pertencem ao mesmo sistema em diferentes níveis. Considerem-se agora duas das teses da teoria de Searle na reconstituição proposta no presente artigo:

(2*) A consciência é uma propriedade sistêmica do cérebro.

(4×) As características (ou propriedades) subjetivas e objetivas são diferentes.

Diante das considerações feitas acima, deve ficar completamente claro que essas teses são perfeitamente compatíveis, já que a consciência é uma propriedade sistêmica subjetiva e, além dela, os sistemas cerebrais, bem como os eventos que neles ocorrem, possuem propriedades objetivas. Entretanto, mesmo que essa aparente contradição esteja afastada, isso ainda não é o suficiente para se aceitar a consistência da teoria de Searle, pois é necessário considerar mais uma vez suas teses referentes ao tema da causação mental.

\section{O PROBLEMA DA CAUSAÇÃO MENTAL}

Conforme discutido na introdução deste artigo, parece ser possível deduzir a partir de algumas teses defendidas por Searle asserções que ele explicitamente nega, o que parece evidenciar que sua teoria da relação mente-corpo (cuja noção central é a de consciência) é incoerente. Cabe agora investigar se a concepção de uma identidade de ocorrências assumida por ele em Searle (2004, p. 125) - e a consequente reformulação da tese (4) - é capaz de eliminar as indesejáveis conclusões $\left(\mathrm{C}_{1}\right)$ e $\left(\mathrm{C}_{2}\right)$.

Penso que a resposta para essa questão é negativa. A conclusão $\left(\mathrm{C}_{1}\right)$ equivale à afirmação de que os comportamentos humanos são sobredeterminados, isto é, possuem, simultaneamente, duas causas: tanto os processos cerebrais quanto os estados de consciência. A 
sobredeterminação seria uma consequência das asserções de que a consciência é causalmente eficaz sobre o comportamento humano, de que os processos cerebrais são causalmente eficazes sobre $o$ comportamento humano e, por fim, da asserção de que a consciência e os processos cerebrais não são idênticos. Penso que esse panorama não se altera significativamente se a tese (4) - tal como a reconstituí em Prata (2008): a consciência e os processos cerebrais não são idênticos for reformulada na tese $(4 \times)$ - tal como reconstituída no presente trabalho: as propriedades subjetivas e objetivas são diferentes. Em primeiro lugar, considerando sua adesão ao ponto de vista neurocientífico, Searle, ao considerar os processos cerebrais como causalmente eficazes sobre o comportamento humano, tem de estar comprometido com a ideia de que esses processos são causalmente eficazes em virtude de suas propriedades objetivas (tanto no nível micro quanto no nível macro), que são aquelas estudadas pelas neurociências, de modo que a afirmação da eficácia causal das propriedades subjetivas é um acréscimo às capacidades causais neurobiológicas, o que leva à sobredeterminação. Em segundo lugar, o modo como Searle argumenta para a irredutibilidade ontológica, fundamentando-a em um modo de existência subjetivo (Searle (1992, p. 117); (2004, p. 120-1)) e considerando as teorias fisicalistas essencialmente incapazes de dar conta dessa subjetividade no modo de existência (cf. Searle (1992, p. 30)), parece claramente comprometê-lo com um dualismo de propriedades, o qual, somado à recusa do epifenomenalismo, leva à sobredeterminação. Em outras palavras, dizer que se trata de um mesmo sistema, mas de propriedades ontologicamente diversas, as subjetivas e as objetivas, que seriam, ambas, causalmente eficazes, deixa o naturalismo biológico atrelado à conclusão $\left(\mathrm{C}_{1}\right)$.

A conclusão $\left(\mathrm{C}_{2}\right)$, por sua vez, exprime uma adesão ao epifenomenalismo, isto é, a concepção de que os fenômenos mentais conscientes são um subproduto causalmente inerte de atividade cerebral. Ela se segue à aceitação da eficácia causal dos processos cerebrais, da negação da identidade entre estes e a consciência e da 
negação da sobredeterminação. Novamente, a reformulação da tese (4) na tese $(4 \times)$ não altera o panorama. A aceitação da eficácia causal dos processos cerebrais, numa concepção científica, só pode conceber essa eficácia como decorrente de suas propriedades objetivas, de modo que a distinção entre propriedades objetivas e subjetivas não permite que se atribua qualquer eficácia causal a estas últimas. Além disso, o epifenomenalismo está estreitamente vinculado a outras teses defendidas por Searle. Em uma passagem onde ele formula a noção de redução causal em termos gerais ele afirma que um fenômeno é causalmente redutível a outro quando "não tem poderes causais em adição aos poderes causais" (Searle (2004, p. 119)) desse outro fenômeno. E, naturalmente, o mesmo valeria para o caso da redução causal da consciência. Searle afirma que: "a consciência é causalmente redutível a processos cerebrais, porque (...) a consciência não tem capacidades causais por si mesma em adição às capacidades causais da neurobiologia subjacente" (Searle (2002b, p. 60), grifo meu), o que parece claramente uma formulação do epifenomenalismo. ${ }^{8}$

\section{CONSIDERAÇÕES FINAIS}

Não creio que a tese da irredutibilidade dos fenômenos mentais a processos cerebrais leve necessariamente ao dilema entre epifenomenalismo e sobredeterminação causal, mas sim que o modo

${ }^{8}$ Justamente essa concepção de redução causal levou Tim Crane a considerar que o naturalismo biológico acaba resultando em uma forma de epifenomenalismo: "[Searle] pensa que essas propriedades [mentais] podem ser 'causalmente reduzidas' às propriedades físicas que subjazem a elas (Searle (1992, p. 114-15)). Mas onde isso deixa os poderes causais do mental? (...) uma vez que a dor e o estado neurológico não são idênticos, mesmo que as capacidades causais da dor sejam inteiramente explicáveis em termos das do estado neurológico, parece claro que na visão de Searle o estado neurológico é a causa real.” (Crane (1993, p. 319-20)).

Manuscrito - Rev. Int. Fil., Campinas, v. 34, n. 2, p. 557-578, jul.-dez. 2011. 
como Searle concebe essa irredutibilidade é que deixa sua teoria enredada com esse problema. Penso que isso ocorre porque a sua concepção de irredutibilidade trafega por um território excessivamente afastado do fisicalismo (o que não é o caso de todas as concepções antireducionistas). Para Searle, a irredutibilidade decorre de uma suposta diversidade dos modos de existência da consciência e dos processos cerebrais, o que não se coaduna com a concepção de que os fenômenos mentais fazem parte da realidade física. ${ }^{9}$ Como visto acima (cf. seção 2) ele considera a subjetividade como uma característica que distingue os fenômenos mentais conscientes de tudo mais no universo (cf. Searle (1992, p. 93)), o que, a despeito de sua afirmação de que o mental é físico $^{10}$, resulta em uma forma de dualismo, entre subjetividade e objetividade ontológicas.

O caráter dualista do naturalismo biológico transparece também no teor de suas críticas ao fisicalismo em filosofia da mente. De acordo com Searle, as diversas objeções que podem ser feitas às teorias fisicalistas da mente, no final das contas, podem ser reduzidas a uma dificuldade fundamental: tais teorias, simplesmente, não dizem respeito à mente, que elas deveriam explicar. Segundo ele, apesar das críticas ao fisicalismo assumirem uma forma mais ou menos técnica, a objeção fundamental a este pode ser formulada de maneira simples: "a teoria [fisicalista] em questão deixou a mente de fora; deixou de fora alguma característica essencial da mente" (Searle (1992, p. 30), grifo meu). A ideia de que uma teoria baseada em fenômenos físicos é incapaz de dar conta de características essenciais da mente, implica que tais características não são de natureza física.

\footnotetext{
${ }^{9}$ Andreas Kemmerling (1994, p. 438) ressalta que o simples uso da expressão "modo de existência" sugere a afinidade do naturalismo biológico com o dualismo de Descartes, que atribuía dois "modi essendi" às coisas existentes, delimitados pelos atributos da extensão e do pensamento.

10 "A consciência é uma propriedade mental, e portanto física, do cérebro" (Searle (1992, p. 14)).
}

Manuscrito - Rev. Int. Fil., Campinas, v. 34, n. 2, p. 557-578, jul.-dez. 2011. 
Em virtude do caráter dualista de seu anti-reducionismo em filosofia da mente é que Searle acaba diante do dilema entre epifenomenalismo e sobredeterminação, e é o dualismo de propriedades corporificado na tese $(4 \times)$ que torna sua teoria da mente incoerente, já que esta tese possibilita a dedução das conclusões $\left(\mathrm{C}_{1}\right)$ e $\left(C_{2}\right)$, que ele explicitamente nega (cf. Searle (2004, p. 207); (2002b, p. 62)). Porém, para assegurar essa avaliação sobre o naturalismo biológico, é importante que algumas objeções possíveis sejam examinadas.

Em primeiro lugar, comentando em termos bastante gerais o debate mente-corpo, Searle rejeita a avaliação de que sua teoria é incoerente afirmando que as concepções tradicionais estão presas à oposição entre dualismo e fisicalismo, porque elas assumem um dualismo de conceitos (cf. p. ex. Searle (1992, p. 26)). A ideia de que o físico e o mental se excluem (de modo que se algo é físico não pode ser mental, e vice versa) seria o que faz o fisicalismo e o dualismo tradicionais parecerem as duas únicas opções possíveis. Ao recusar esse dualismo conceitual, Searle acredita ter tornado plausível uma posição como a sua, que congrega aspectos do dualismo e do fisicalismo, ainda que em uma nova versão (cf. Searle (2002b, p. 62-3); (2004, p. 126)). Porém, essa linha de argumentação não me parece convincente, pois conforme procurei mostrar em outro trabalho (cf. Prata (2009, p. 117)) o modo como Searle concebe a irredutibilidade ontológica da consciência acaba levando a uma forma de dualismo entre conceitos subjetivos e objetivos (cf. Searle (2004, p. 120)), o que torna vazias as reflexões dele sobre uma superação do dualismo conceitual. E é o dualismo entre o subjetivo e o objetivo que leva às incoerências discutidas no presente trabalho.

Em segundo lugar, é importante notar que, ciente das críticas à sua filosofia da mente, Searle se esforçou para rejeitar a avaliação de que ela consiste em uma forma de dualismo de propriedades (cf. Searle (2002b)). Seus argumentos são, principalmente: (a) que o naturalismo 
biológico não divide o mundo em duas categorias ontológicas fundamentais, pois "o próprio ato de categorização é sempre relativo a interesses" (Searle (2002b, p. 59)); e (b) que a irredutibilidade ontológica da consciência não implica que ela seja algo "acima e além" dos processos cerebrais, uma vez que a consciência é causalmente redutivel a esses processos. Exatamente a viabilidade de uma redução causal da consciência à atividade cerebral é que evitaria o dilema entre epifenomenalismo e sobredeterminação causal (cf. Searle (2002b, p. 612)). Mas, novamente, não considero a argumentação de Searle bemsucedida. A afirmação de que ele não divide o mundo entre duas categorias esgotantes é desmentida em diversas passagens onde Searle discute a subjetividade ontológica (cf. Searle (1992, p. 93); (2002a, p. 39)). Como explica David Hodgson (1994, p. 265), a pretensa superação do dualismo entre o mental e o físico não é de grande valia, pois Searle acaba caindo em uma cisão entre o modo de existência subjetivo e o objetivo, que não é significativamente diferente do dualismo entre o físico e o mental. Além disso, a concepção de redução causal não é capaz de afastar o dualismo de propriedades. Como vimos, a redutibilidade causal da consciência implica que: (1a) as características da consciência são causalmente explicáveis através dos processos cerebrais, e (1b) as capacidades causais da consciência são as mesmas que as desses processos. Entretanto, o modo como Searle concebe a explanação, a saber, enquanto a constatação de relações causais entre processos cerebrais e estados de consciência é muito fraco, pois é perfeitamente compatível com a hipótese de que as relações causais se dão entre entidades de domínios ontológicos independentes (tal como professava Descartes com seu dualismo interacionista). Por sua vez, a identidade das capacidades causais, conforme exposto acima (cf. o final da seção 4), é formulada por ele em termos muito próximos do epifenomenalismo, de modo que esse aspecto da redução causal não parece capaz de afastar o dualismo de propriedades. 
Diante desses resultados, penso que a única maneira como Searle poderia tornar sua teoria coerente seria reelaborando sua concepção de irredutibilidade, de um modo que fosse compatível com o fisicalismo. Seguindo a linha do fisicalismo não-redutivo, que para alguns autores tem certa proximidade com sua teoria ${ }^{11}$, Searle deveria articular a não identidade entre propriedades subjetivas e objetivas de um modo que pudesse ser conciliado com algum tipo de relação de dependência das primeiras com as segundas (cf. Schlosser (2009, p. 74-5)). ${ }^{12}$ Evidentemente, isso não garantiria que o naturalismo biológico fosse verdadeiro, mas, pelo menos, faria dessa teoria uma candidata à verdade, isto é, uma teoria defensável, digna de atenção no debate filosófico.

\section{REFERÊNCIAS BIBLIOGRÁFICAS}

CHURCHLAND, P. "Betty Crocker's Theory" (Review on The Rediscovery of The Mind). London Review of Books. Vol. XVI, Number 9 (12 May), pp. 13-14, 1994.

CORCORAN, K. “The Trouble with Searle's Biological Naturalism”. Erkenntnis, 55, pp. 307-324, 2001.

11 A respeito da teoria de Searle sobre a consciência Suzanne Cunningham afirma que: "algumas de suas afirmações soam razoavelmente próximas da versão fraca de dualismo de propriedades (ou fisicalismo não-redutivo) que eu descrevi" (Cunningham (2000, p. 34)). Na visão dessa autora, o fisicalismo não-redutivo seria um dualismo fraco de propriedades por ser mais um dualismo entre teorias do que um dualismo ontológico.

12 Jaegwon Kim considera o fisicalismo não-redutivo como um dualismo de propriedades atenuado, porque essa forma de fisicalismo alia a irredutibilidade ontológica das propriedades mentais a uma relação de dependência entre estas e as propriedades físicas (cf. Kim (1993, p. 340)). 
CRANE, T. Review on The Rediscovery of The Mind. International Journal of Philosophical Studies Volume 1. Number 2. September, pp. 313323, 1993.

CUNNINGHAM, S. What is a Mind?: an Integrative Introduction to the Philosophy of Mind. Indianapolis: Hackett Publishing, 2000.

DENNETT, D. Review on The Rediscovery of The Mind. The Journal of Philosopby 90(4), pp. 193-205, 1993.

GREWENDORF, G.; MEGGLE, G. (eds.). Speech Acts, Mind and Social Reality: Discussions with John R. Searle. Dordrecht, Boston, London: Kluwer Academic Publishers, 2002.

GUTTENPLAN, S. (ed.) A Companion to the Philosophy of Mind. Oxford/Cambridge MA: Basil Blackwell, 1994.

HIEKE, A.; LEITGEB, H. (eds.) Reduction: Between the Mind and the Brain. Frankfurt, Paris, Lancaster, New Brunswick: Ontos Verlag, 2009.

HODGSON, D. "Why Searle has not Rediscovery the Mind". Journal of Consciousness Studies, 1, n 2, Winter, pp. 264-274, 1994.

KEMMERLING, A. "Von der Sprache zum Bewusstsein: John R. Searle löst sich vom analytischen Mainstream". Merkur - deutsche Zeitschrift für europäisches Denken. 48, 5. pp. 432-8, 1994.

KIM, J.; JAKOB, P. et al. "Searle Symposium". Philosophy and Phenomenological Research. Vol. LV, no 1, march, pp. 189-232, 1995.

KIM, J. Supervenience and Mind: Selected Philosophical Essays. Cambridge UK: Cambridge University Press, 1993. . Philosophy of Mind. Boulder CO: Westview, 1996.

NAGEL, T. "The Mind Wins!" (Review on The Rediscovery of The Mind). New York Review of Books March 4, pp. 37-41, 1993. 
OLAFSON, F. A. "Brain Dualism" (Review on The Rediscovery of The Mind]). Inquiry (37), pp. 253-256, 1994.

PLACE, U. T. "Thirty Years On - Is Consciousness Still a Brain Process?". Australasian Journal of Philosophy (66) 2, pp. 208-219, 1988.

PRATA, T. A. "Dificuldades da concepção de John Searle sobre a redução da consciência: o problema das capacidades causais". Princípios, vol. 15, n 24, pp. 5-29, 2008.

- "Irredutibilidade ontológica versus identidade: John Searle entre o dualismo e o materialismo". O que nos faz Pensar $\mathrm{n}^{\circ}$ 25, pp. 107-124, agosto de 2009.

PRESTON, J.; BISHOP, M. (Eds.) Views into the Chinese Room: New Essays on Searle and Artificial Intelligence. Oxford: Oxford University Press, 2002.

SCHLOSSER, M. E. "Nonreductive Physicalism, Mental Causation, and the Nature of Actions". In: A. Hieke, H. Leitgeb (eds.) (2009), pp. 73-89.

SCHRÖDER, J. "Searles Auffassung des Verhältnisses Von Geist und Körper und ihre Beziehung zur Identitätstheorie". Conceptus XXVI, Nr. 66, pp. 97-109, 1992.

SEARLE, J. R. "Minds, Brains and Programms". Behavioral and Brain Sciences, 3, pp. 417-424, 1980a. . "Intrinsic Intentionality". Behavioral and Brain Sciences, 3, pp. 450-457, 1980b. 
SEARLE, J. R. Intentionality: a Essay in the Philosophy of Mind. Cambridge: Cambridge University Press, 1983.

- The Rediscovery of the Mind. Cambridge Mass., London: MIT Press, 1992. “Searle, John”. In: S. Guttenplan (ed.) (1994), pp. 544550.

."Consciousness, the Brain and the Connection Principle: a Reply". Philosophy and Phenomenological Research. Vol. LV, $\mathrm{n}^{\circ} 1$, march, pp. 217-232, 1995.

- Consciousness and Language. Cambridge (UK): Cambridge University Press, 2002a.

.Why I Am Not a Property Dualist" Journal of Consciousness Studies, 9, $\mathrm{n}^{\circ}$ 12, pp. 57-64, 2002b.

2004.

. Mind: a brief introduction. Oxford: Oxford University Press,

SMITH, B. (Ed.). John Searle. Cambridge: Cambridge University Press, 2003.

SNOWDON, P. F. Review on The Rediscovery of The Mind. The Philosophical Quarterly (44), pp.259-260, 1994.

STEWARD, H. The Ontology of Mind: Events, Processes, and States. Oxford: Oxford University Press, 2003.

STICH, S.P. Review on Minds, Brains and Science. The Philosophical Review (96), pp.129-133, 1987.

TSOHATZIDIS, (Ed.) John Searle's Philosophy of Language: Force, Meaning and Mind. Cambridge: Cambridge University Press, 2007.

VANDERVEKEN, D. et. al. Revue Internationale de Philosophie 2, n 217, pp. 165-297, 2001. 